\title{
Demonstration of a Mobile Education Artifact in a Tanzania's Higher Education Institution
}

\author{
https://doi.org/10.3991/ijim.v14i14.13195 \\ Godfrey Isaac Mwandosya $\left({ }^{\square}\right)$ \\ College of Business Education, Dar es Salaam, Tanzania \\ g.mwandosya@cbe.ac.tz \\ Calkin Suero Montero, \\ University of Eastern Finland, North Karelia, Finland \\ Esther Rosinner Mbise \\ College of Business Education, Dar es Salaam, Tanzania \\ Solomon Sunday Oyelere \\ University of Eastern Finland, North Karelia, Finland
}

\begin{abstract}
This study reports the demonstration of the effectiveness of a mobile education tool (MET) that was co-designed and developed at the College of Business Education (CBE) in Tanzania by a team of teachers, researchers, and a developer using the Design Science Research (DSR) methodology. The demonstration of the CBEMET Prototype as an artifact was done to 30 teachers who had participated in the co-designing of the prototype phase, 3 members of CBE management team and 20 students in Bachelor II degree program as the observers and representative of those who will use the prototype at a later stage. Different sets of questionnaires were administered to the teachers, the members of management team and the students. The demonstration confirmed that it is easy to access the prototype, share learning contents, and provide education through mobile devices. Nonetheless, teaching materials prepared for testing the prototype were insufficient and thus needed improvement. Furthermore, teachers and observers proposed for more options to the prototype such as the inclusion of timetable, alerts of events like examination dates, and news on innovation activities. The feedbacks from the participants have thus been considered to reduce errors in the usage of the prototype before its final deployment.
\end{abstract}

Keywords - Mobile education tool, demonstration, evaluation, Design science research, CBE, Tanzania.

\section{Introduction}

The benefits of using tools in education in higher education institutions have attracted several institutions in developing countries. The use of teaching aids improves 
achievement and success of students. Without teaching aids, learning processes will be poor and less effective. ICT technology is among the key aids in teaching and learning processes being advocated in developing countries like Tanzania [1], [2]. Information and communication technologies (ICTs), in particular, have changed the way education is delivered, consumed, transmitted, and applied by both teachers and students [3], [4]. Electronic learning (e-learning), for instance, enables access to distant educational resources, which enhances innovation in teaching and learning in higher education sector [5]. Kukulska-Hulme, [6] writes that the use of tablets, smartphones, and portable device assistants (PDAs) with wireless internet connections have extended the e-learning and enabled the teaching and learning to take place anywhere anytime ubiquitously [6].

The design and development of mobile education applications (mobile apps) is an important development in technology and education. Contemporarily, there is a plethora of mobile education applications for enhancing the teaching and learning in higher education institutions (Hevner et al., [7], Hevner \& Chatterjee [8], and Johannesson \& Perjons [9]). These mobile education apps solve practical problems facing both teachers and students in most of the emerging economies like Tanzania, such as problems of accessing materials for self-learning, inadequate classrooms, shortage of teaching aids, and equipment in schools and rural areas, just to mention a few [12]. Oyelere, et al., [10], for example, designed and developed MobileEdu to help students in a Nigerian University to learn computer science subject and enhance their understanding.

In Tanzania's higher education context, efforts to use ICTs and e-learning as pedagogical way to the teaching and learning started about a decade ago [11], [12], [1]. and has been very popular among teachers and students in higher education institutions in Tanzania in recent years [13], [14], [15]. Teachers and students, for example, use mobile devices installed with mobile apps that when accessed enables the exchange educational materials and share knowledge and experience.

However, there are still challenges in using mobile education tools despite abundant benefits they offer in the education and other sectors. Mtebe and Raisamo [16] report challenges such as the lack of Internet and lowness of Internet bandwidth, absence of policies, and lack of skills to design online materials as hindering agents to the success of mobile education tools for mobile learning where open educational resources in the focal point. Also, Grimus et al., [17] report on some of the educational challenges where mobile learning steps in to improve and solve the challenges so observed. In addition, Mtebe and Raisamo [18] report that teachers have challenges in preparing, organizing, and using the online open resources materials. Furthermore, involvement of teachers as users in defining their problems for technological solution has been another challenge [19]. According to Krogstie [20], IT artifacts' design must involve users in all stages. Lack of the involvement of the would-be users often leads to the unpopularity of such artifacts, which hampers their abilities to solve the practical problems they are intended for. This implies the need to look at the way these applications or artifacts are designed and developed in the context in which they are used. In real sense one expects that the whole process from initial ideas of acquiring an artifact right to the design and development should be as systematic as possible. It is in this light that the CBEMET prototype design strictly followed The DSR frame- 
work1. DSR Framework ensures that the designed artifact is acceptable to the user and solves practical problems facing a certain organization or individuals. DSR framework, among other things, involves several iterations in the design and development of IT artifacts for the sake of quality.

One key step in the development of an artifact through DSR framework is demonstration [9]. Demonstration of an artifact before engaging it fully-fledged in the environment provides an opportunity for checking its suitability provides a room for corrections and improvement of the artifact and evades failures of the prototype in the actual context.

This study therefore narrates one of the steps of DSR known as demonstration which is about showing the users (in this study the teachers at CBE, management team, and students) how the CBEMET Prototype as an artifact that has been developed functions. In this case, the artifact is initially evaluated and the feedback from the demonstration process is used to improve the artifact.

Section 2 of the paper narrates the activities undertaken in the design and development of the CBEMET Prototype. Section 2 describes the methodologies used in demonstrating the prototype and the initial evaluation. Section 4 describes findings of the study. The next two sections are discussion and conclusion, respectively.

\section{Evolution of the CBEMET Artifact}

The CBEMET Prototype was designed and developed in line with the Design Science Research (DSR) framework. The DSR framework entails a systematic approach to solving practical problems through artifacts. According to Johannesson and Perjons [9], an artifact is an object made by humans to address a practical problem. There are several scholars who have described the DSR framework for example [8], [21], [7]. In this study, though, we had adopted the DSR framework as articulated by Johannesson \& Perjons [9].

Teachers at the College of Business Education had long been using traditional face-to-face teaching the most. The introduction of one learning management system in 2011 known as students and registration information system (SARIS) started an era of technology application in the teaching and learning at CBE. The application was mainly used for processing examination. However, unlimited number of bugs in the system would from time to time hamper access to its different functionalities. Likewise, many of its functionalities were either under construction or poorly performed. In this backdrop, some teachers at CBE who had been using SARIS reverted to normal tedious manual examinations processing. The crucial point here is that an involvement of teachers in requirements definition of the application would have averted these shortcomings. It would enable the designers to deeply understand the practical problems faced by teachers in their teaching process. The use of technologies in the academic arena has proved be facing challenges when the users of the technolo-

\footnotetext{
${ }^{1}$ DSR is well explained in Design Science Research [9], [8].
} 
gies are either reluctant or the technological solution is not addressing their practical problems [16]. It is therefore, important for developers of these mobile education applications to involve the users of the technology applications right from the initial stages of the technology acquisition [22].

\subsection{Requirements definition by teachers at the college of business education}

We conducted a study with teachers to identify the requirements of teachers at the College of Business Education for an artifact that suits their practical problems [23]. Some of the identified practical problems were the lack of mobile training, mismatch of the teaching materials for the same courses in different campuses, crowded classrooms, inadequate teaching aids, and scarce resources. The study also revealed that most teachers at $\mathrm{CBE}$ had one or more mobile devices, which they were willing to use for teaching.

\subsection{Designing and developing the CBEMET prototype}

The design and development of the CBEMET Prototype followed the problem explication stage which was conducted at CBE. The explication exposed the need for the mobile training application and the need for proper sharing of educational materials by all teachers. Similar works on applying the DSR with participatory design has been done in Tanzania, for example Kapinga et al., [24]. Following the explication process, the requirements definition was done by teachers, researchers, and a developer. The problem explication, definition of requirements and the co-designing and development of the CBEMET Prototype followed DSR framework by Johannesson \& Perjons [9]. The stages followed were problem explication, requirements definition, design and development, demonstration and evaluation of the artifact (see Figure 1).

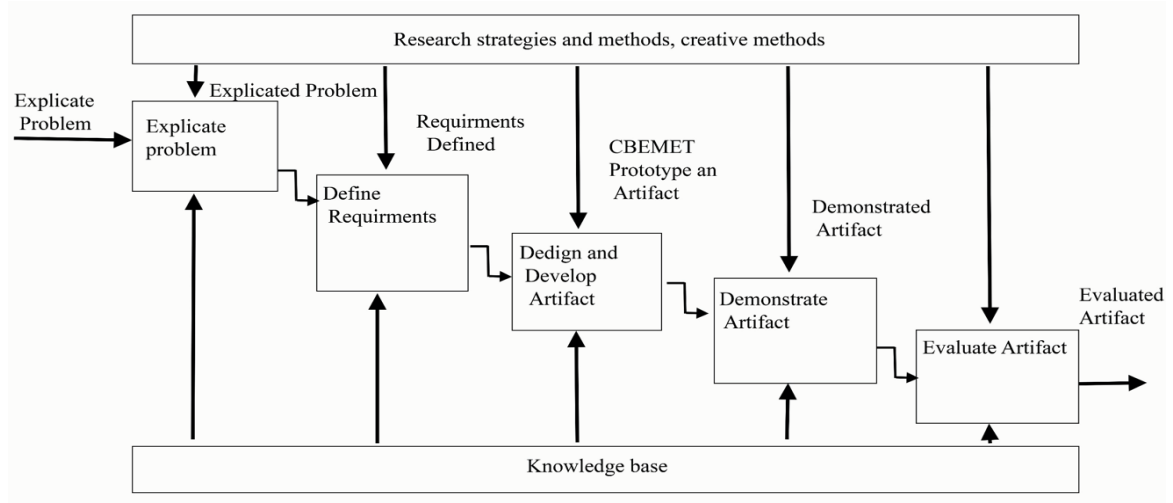

Fig. 1. Stages of DSR framework by Johannesson and Perjons [9] applied in the co-design and development of the CBEMET Prototype. 


\subsection{Explication of the problem}

According to Johannesson and Perjons, [9], explicating the problem is an activity that is about investigating and analyzing a practical problem in a particular context. The problem needs to be precisely formulated and justified by proving that it is significant and of general interest even for global practice. In fact, in DSR, and according to Johannesson and Perjons, this is the first stage in the DSR involving the investigation of the practical problem at hand, analyzing it to find out if it's worth effort to solve through developing an artifact [9]. The problem at the College of Business Education was a transition from depending on face-to-face teaching to using technologies in learning. This caused challenges that call for an artifact to mitigate against.

\subsection{Defining requirements}

According to Peffers et al., [21], since the problem definition will be used to develop the artifact that can effectively provide a solution, it may be useful to atomize the problem conceptually so that the solution can capture its complexity. According to Johannesson and Perjons, [9], the activity that leads to defining requirements should outline a solution to the explicated problem in the form of an artifact and elicits requirements, which can be seen as a transformation of the problem into demands on the proposed artifact. Defining the requirements means that the explicated problems are set to narrate what an artifact will have to do to solve the practical problems observed. The requirements definition, in other words, is a proposal document or statement that a team of developers of the artifact should follow in order to design and develop a real artifact. Braun et al., [25], in a bid to clarify some confusing issues about understanding DSR, emphasized and demonstrated that requirements definition is a crucial in DSR. At the College of Business Education, teachers were involved in defining the requirements definition for the proposed artifact. The proposed artifact was named the CBEMET Prototype and was intended to provide the mobile training to teachers and to enable them to share educational-related materials online from a single source. It would also enable sharing of the same educational materials across all campuses for the sake of quality and equality.

\subsection{Designing and developing the artifact}

Once the requirements have been revealed, what follows is a design and develop the artifact. In a study by Peffers et al., [21] the design and develop is the activity 3 create the artifact. This activity includes determining the artifact's desired functionality and its architecture and then creating the actual artifact. According to Johannesson and Perjons [9], design and develop is the third activity. The design and develop artifact activity create an artifact that addresses the explicated problem and fulfils the defined requirements. Designing an artifact includes determining its functionality as well as its structure.

The CBEMET Prototype was co-designed and developed in teamwork manner that included teachers of Dar es Salaam campus, one developer, and three researchers (see 
Figure 2). The design and the development of an artifact followed the requirements definition by the prospective users at the College of Business Education. After designing and developing the artifact, the demonstration was done to determine the functionality and the structure of the artifact [9], [21].

\subsection{Demonstration of the artifact}

The demonstration of the artifact is the activity 4 in both studies by Peffers et al., [21] and Johannesson and Perjons [9], [21], [9]. According to Peffers et al., [21], this activity demonstrates the use of the artifact to solve one or more instances of the problem. This could involve its use in the experimentation, simulation, case study, proof, or other appropriate activity. Furthermore, according to Johannesson and Perjons [9], demonstrate the artifact is uses the developed artifact in an illustrative or real-life case, sometimes called a "proof of concept", thereby proving the feasibility of the artifact

Demonstration of an artifact being the fourth activity in DSR framework, its functions as a "check point", where prospective users get a glimpse of how the prototype works. During the demonstration, users assess whether the prototype can at least solve an instance of the problem at hand. In this backdrop, a demonstration should be done in a real-life setting to meaningfully asses its functions.

\subsection{Evaluation of the artifact}

According to Peffers et al., [21], evaluation of the artifact observes and measures how well the artifact supports a solution to the problem. This activity involves comparing the objectives of a solution to actual observed results from use of the artifact in the demonstration.

The evaluation of an artifact is the last stage in the DSR model by Johannesson and Perjons [9] and is the last but one in the DSR model described by Peffers et al., [21]. It determines how well the artifact has fulfilled the requirements definition and the extent to which it has solved or alleviated the practical problem that motivated the research.

During the workshop, teachers provided a proposal of a tentatively designed prototype menu from the scratch to be considered before a fully-fledged prototype. The researchers and the developer considered all ideas and requirements of the users in their sketches and the resulting menu for teachers was developed (see figure 2). 


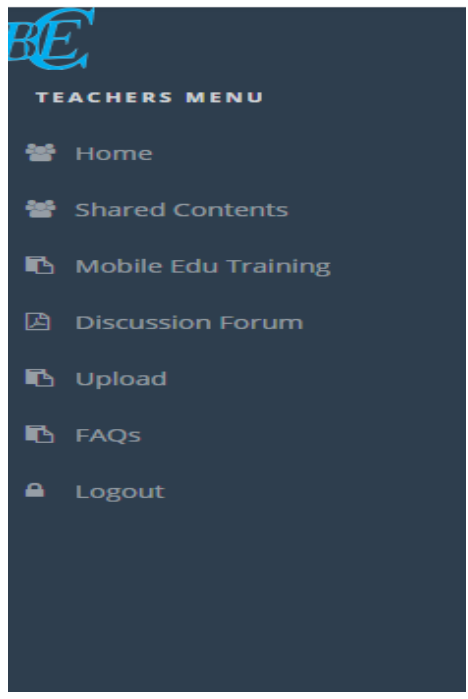

Fig. 2. The CBEMET Prototype menu

\section{$3 \quad$ Research Design and Context}

\subsection{Approach}

Preparation: The demonstration process was set to be done in Block A boardroom at the Dar es Salaam main campus of the College of Business Education on the 20th September 2019. One of the conditions agreed upon was that the boardroom should have internet connections for the teachers to access the CBEMET Prototype using their mobile devices or laptops. Furthermore, items to focus during the demonstration were also provided to all the participants to ease their understanding of the presentation.

Other obligatory equipment was a projector, flip chart, notebooks, and ball pens for the teachers to note down any discrepancy, or anything that inspired their curiosity.

Participants: The 2 researchers, 30 teachers and a developer participated in the demonstration of the CBEMET Prototype. Furthermore, some 3 members of the CBE management team and 20 bachelor II degree students participated as observers of the exercise also as potential users of the prototype when fully developed as an application.

\subsection{Demonstration method - The functioning of the CBEMET prototype}

Instructions given to all participants were as follows:

1. Download the app into your mobile device 
2. Start the app on your mobile device by clicking on the icon the CBEMET Prototype

3. Enter username and password

4. Proceed to navigate through different facilities found in the prototype

5. Logout

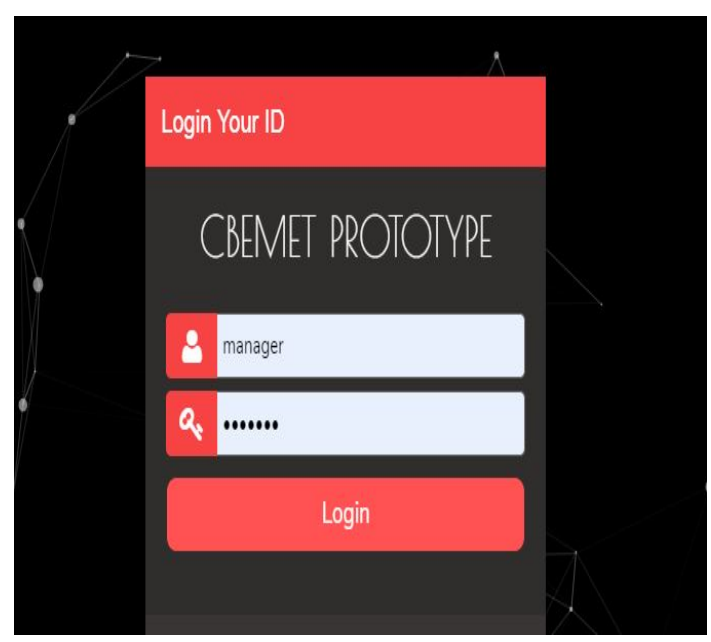

Fig. 3. The login menu of the CBEMET Prototype

During the demonstration, the developer of the prototype was actively engaged to explained and respond to all technical difficulties faced by the participants and finally taking notes where the need of improvement was inevitable.

The Demonstration of the CBEMET Prototype: The demonstration of the CBEMET Prototype involved two types of participants; 30 teachers from CBE campus in Dar es Salaam who were the performers and invited participants whose roles were to independently observe the processes, take notes, and provide feedback for improving the prototype.

The two main activities in the demonstration of the CBEMET Prototype were:

1. Justifying the choice of the case - This was done by explaining to the participants why the chosen case is representative of the problem and is challenging enough to offer an adequate test and

2. Clarifying the parts of the artifact tested - This is a description of the components of the artifact that are used in the demonstration.

Moreover, the checklist was provided to the participants to guide them on what to exactly concentrate on during the demonstration process. The design chosen for the demonstration was an experiment, whereby, the participants were asked to actively access and use the prototype according to the activities shown in Table 1. The experiment design was deemed ideal for this demonstration because of its effectiveness in fictitious and real-life settings [9]. 
Table 1. Focused tasks during the demonstration of the designed case

\begin{tabular}{|l|l|}
\hline S/No. & \multicolumn{1}{|c|}{ Activities } \\
\hline 1. & Accessing the CBEMET Prototype - as demonstrated \\
\hline 2. & Attending mobile education training online \\
\hline 3. & Uploading education materials for sharing \\
\hline 4. & Downloading education materials from others \\
\hline 5. & Logging out \\
\hline
\end{tabular}

It was agreed that the activities mentioned in Table 1 were well set and satisfactory for demonstrating the functionalities of the CBEMET Prototype to participants. It was also agreed that the role of the observers would be looking at the functionalities of the CBEMET Prototype from an external perspective as free agents. The reason behind this agreement was that the invited guests would provide additional or extra ideas and suggestions that might have been overlooked in the earlier process of co-designing and developing the CBEMET Prototype by the teachers, researchers, and the developer.

The boardroom was set up with the local area network of the CBE and Wi-Fi to facilitate the internet to all participants with variety of devices such as desktop computers, laptops, PDAs, tablets, projector, and a flipchart.

The Demonstration Process: The demonstration process started with the introduction session; whereby, the researcher reminded recipients about the aim of demonstrating the artifact. The introductory note was followed by a narration of how the CBEMET Prototype works. Meanwhile, (teachers observed the process while taking notes and recording questions for clarification.

The demonstration was followed by experiment and observation, that is, teachers did the experiment by focusing items in Table 1, as, the invited participants observed the processes and took notes.

Demonstration of the Artifact itself: In demonstrating the CBEMET Prototype, two activities were undertaken: "choosing or designing a case" and "applying the Artifact" for demonstration. During The application of the Artifact" each activity was recorded. The evidence was being taken in terms of questions directed to the participants (see Table 2).

Table 2. Demonstrated items

\begin{tabular}{|l|l|l|}
\hline \multicolumn{1}{|c|}{ Demonstration Activity } & \multicolumn{1}{|c|}{ Type of Question } & \multicolumn{1}{|c|}{$\begin{array}{c}\text { Response } \\
\text { (Yes/No) }\end{array}$} \\
\hline Accessing the Prototype & Was accessing the Prototype well demonstrated? & Yes/No \\
\hline Mobile Education Training & $\begin{array}{l}\text { Is the availability of online learning materials evi- } \\
\text { dent? }\end{array}$ & Yes/No \\
\hline Uploading materials for sharing & $\begin{array}{l}\text { Is uploading education materials clearly demon- } \\
\text { strated? }\end{array}$ & Yes/No \\
\hline $\begin{array}{l}\text { Downloading shared educational } \\
\text { materials }\end{array}$ & Have you been able to download the materials? & Yes/No \\
\hline
\end{tabular}


The demonstration of how the CBEMET Prototype functions focused the activities in Table 2 which finally resulted into having a chance to see briefly the produced instances of uploaded documents which could be downloaded as well, see Figure 5.

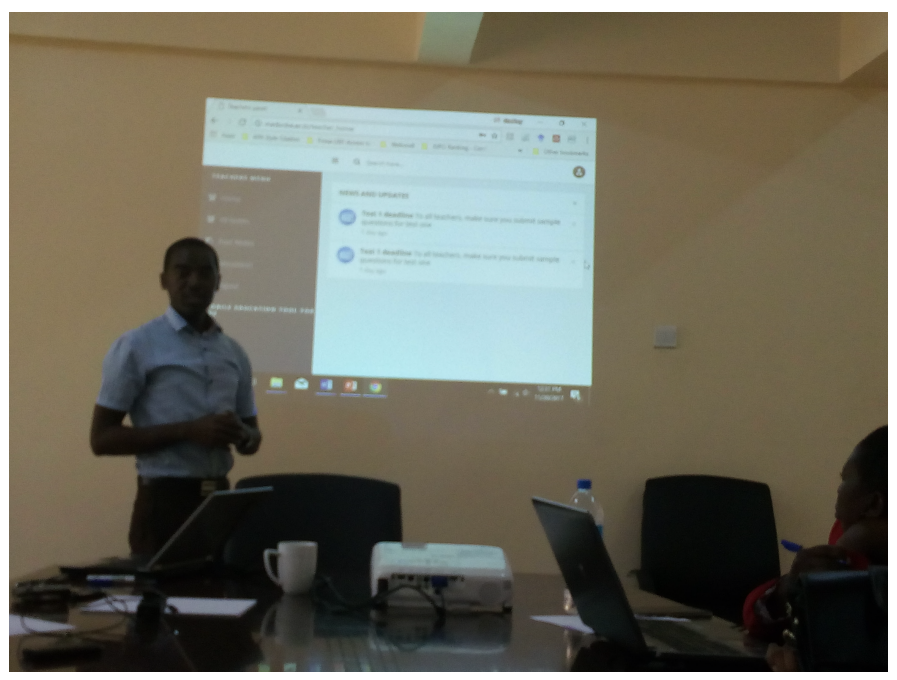

Fig. 4. The demonstration of how to upload and download educational contents through the prototype

The activities in Table 2 were purposely planned for demonstration in order to test the intended and expected functionalities of the CBEMET. The participants were asked to respond "Yes" or "No" to the demonstrated activities.

Input to the demonstration: The input to the demonstration process was the CBEMET Prototype which was demonstrated by the researchers and the developer (Figure 5).

Demonstration of CBEMET prototype: The effective demonstration process starts with a well-prepared plan. In the process, both the users of the prototype and the environment for the demonstration was prepared. The preparation was directed towards the venue with equipment, timetable of the event, which was distributed to all participants, and informing the participants on what they should come with for demonstration purposes for example, their mobile devices.

During the demonstration, there are several ways on which can be followed in order to facilitate it. Designing or choosing a demonstration case goes with looking what has been prepared for demonstration in terms of users and the environment where the demonstration was taking place.

The activity of applying the CBEMET Prototype was the actual demonstration and for the users to access the prototype and start actual using it. At this point is where the details of how the prototype real works was being recorded even by the observers who could provide comments for the improvement of the prototype at later iterations.

Output of the demonstration: The demonstration of the CBEMET Prototype, just like any other artifact, has output as well. The output is a proof that an artifact has at 
least solved an instance of the practical problem. The proof was sought with questionnaire to participants please see (Figure 5).

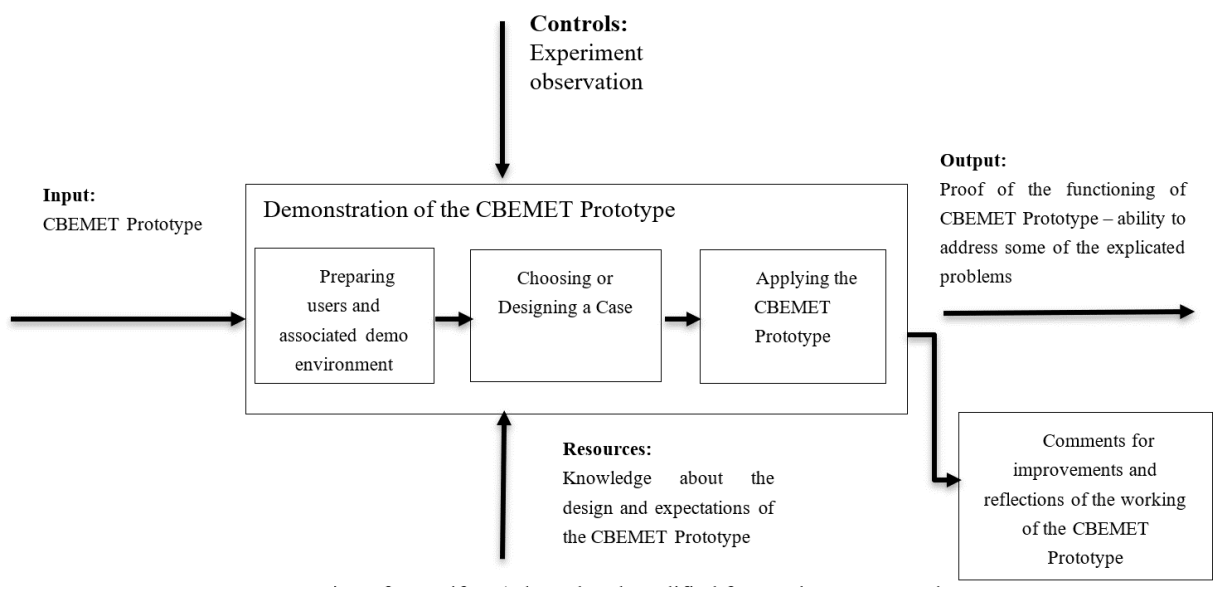

Fig. 5. Demonstration of an artifact (adapted and modified from Johannesson and Perjons [9, p. 134]).

The participants were supposed to indicate their reaction to the demonstration process by answering (Yes/No). Additionally, initial evaluation was done through focus group discussion to gain more insight on the functioning of the CBEMET Prototype, see Figure 6.

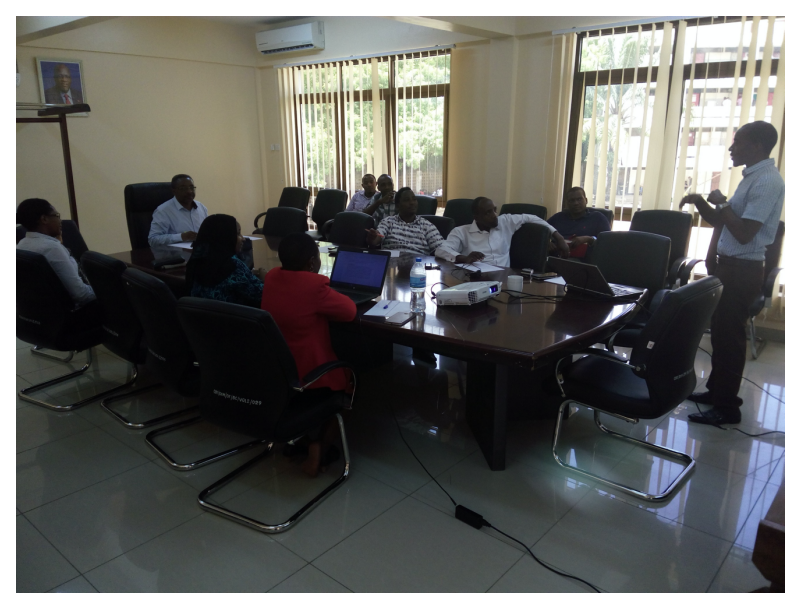

Fig. 6. A narration on the working of the artifact by a developer during the demonstration 


\subsection{Initial evaluation}

The demonstration phase was reinforced by some sort of initial evaluation of the CBEMET Prototype. That is, the participants in the demonstration exercise were at the same time evaluating the prototype. They evaluated whether the CBEMET Prototype had in one way or another mitigated the practical problems which faced teachers and students at CBE. Three items were selected for the purpose of initial evaluation; functionality of the CBEMET Prototype, ability to facilitate the mobile training, and sharing of resources. To these three items, several checking criteria were listed as evaluation point to be evaluated using a Likert scale ranging from 1 - strongly disagree to 5 - strongly agree.

\section{i. Functionality}

- Ease of access of the prototype

- Logging in process

- Ease of navigation through the available facilities of the CBEMET Prototype

- Logging out process

\section{ii. Ability to facilitate mobile training}

- Online access

- Quality of sound

- Quality of the training

iii. Facilitation of resource sharing

- Uploading educational resources

- Availability of resources

- Ease of sharing - how often is feedback prompt?

Table 3. Initial evaluation of the CBEMET Prototype

\begin{tabular}{|c|l|l|l|}
\hline No. & \multicolumn{1}{|c|}{ Item for Initial Evaluation } & \multicolumn{1}{c|}{ Evaluation Check } & \multicolumn{1}{c|}{ Score } \\
\hline 1. & $\begin{array}{l}\text { Functionality of the CBEMET Proto- } \\
\text { type }\end{array}$ & $\begin{array}{l}\text { Ease of access } \\
\text { Login process } \\
\text { Ease of navigation } \\
\text { Logout process. }\end{array}$ & Likert scale 1 - 5 \\
\hline 2. & Ability to facilitate mobile Training & $\begin{array}{l}\text { Accessing online training } \\
\text { Quality of sound } \\
\text { Quality of training. }\end{array}$ & Likert scale 1 - 5 \\
\hline 3. & Facilitation of resources sharing & $\begin{array}{l}\text { Uploading education resources } \\
\text { Facilitation of resource sharing } \\
\text { Ease of sharing }\end{array}$ & Likert scale 1 - 5 \\
\hline
\end{tabular}




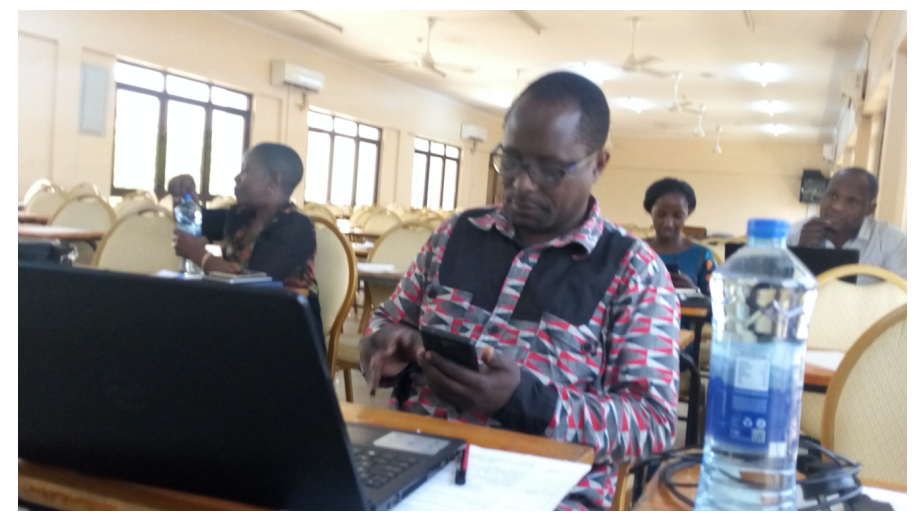

Fig. 7. Teachers checking (initial evaluation) on how the CBEMET Prototype really works

The following section presents findings from the demonstration activities associated with the initial evaluation by the 30 teachers of CBE Dar es Salaam Campus.

\section{Findings}

This section presents results of the demonstration activities that were carried out at the College of Business Education where the CBEMET Prototype was an artifact. The analysis of the data was followed descriptive analysis method. The combination of data and information were obtained through a set of questionnaires distributed to 25 respondents. The IBM SPSS STATISTICS Version 20 Software was used for analysis. The overall analysis of the findings related to the CBEMET Prototype is presented in the form of mean score.

The analysis is divided into two parts as follows:

1. Demographic - Part A

2. Initial evaluation of the CBEMET Prototype (Functionalities, Ability to facilitate mobile training, and Resources sharing) - Part B.

That is, part A of the questionnaire focused demographic details such as gender, education level, and the department where the respondent came from.

PART A - Demography

18 male teachers $(60 \%)$ out 30 respondents actively participated in the demonstration exercise while the female teachers were $12(40 \%)$ please see (Table 4$)$. 
Table 4. Gender of the respondents

\begin{tabular}{|l|c|c|}
\hline & Frequency & Percent (\%) \\
\hline Male & 18 & 60.0 \\
\hline Female & 12 & 40.0 \\
\hline Total & 30 & 100.0 \\
\hline
\end{tabular}

The demonstration of the CBEMET Prototype involved staff from tutorial assistant level (bachelor's degree) to senior lecturer level2 ( $\mathrm{PhD}$.). That is, senior lecturers were $2(6.7 \%)$ out of 30 participants. Assistant lecturers were $26(86.7 \%)$ and tutorial assistants (Post graduate diploma and bachelor's degree) were 2 (6.7\%) (see Table 5).

Table 5. Education levels of the respondents

\begin{tabular}{|l|c|c|}
\hline & Frequency & Percent (\%) \\
\hline PhD. & 2 & 6.7 \\
\hline Master's Degree & 26 & 86.7 \\
\hline Post Graduate Diploma & 1 & 3.3 \\
\hline Bachelor's degree & 1 & 3.3 \\
\hline Total & 30 & 100.0 \\
\hline
\end{tabular}

Further, participants came from six different departments, namely, Accountancy, Business Administration, ICT and Mathematics, Legal and Industrial Metrology, Marketing, and Procumbent and Supplies Management (see Table 6).

Table 6. The participants in the demonstration exercise by their departments

\begin{tabular}{|l|c|c|}
\hline & Frequency & Percent (\%) \\
\hline Accountancy & 4 & 13.3 \\
\hline Business Administration & 6 & 20.0 \\
\hline ICT and Mathematics & 4 & 13.3 \\
\hline Legal and Industrial Metrology & 5 & 16.7 \\
\hline Marketing & 5 & 16.7 \\
\hline Procurement and Supplies Management & 6 & 20.0 \\
\hline Total & 30 & 100.0 \\
\hline
\end{tabular}

One of the criteria used for including teachers in the demonstration of the CBEMET Prototype was their experience in using mobile applications. The previous experience would enable them to use the schema they had acquired from the previous applications to evaluate the CBEMET Prototype. In this endeavor, it was revealed most of the teachers ( 23 out of 30 ) $76 \%$ have experience in using mobile applications

${ }^{2}$ At the College of Business Education like any other higher education institution the academic position starts at tutorial assistant to senior lecturer. For those who are employed as tutorial assistants are normally the best students who have exceptionally passed their examination with flying colors and are retained. They undergo training to master's level and $\mathrm{PhD}$ levels. 
ranging from 4 to 6 years thereby making the introduction of the CBEMET Prototype to be not new and strange experience whatsoever (see Table 7.).

Table 7. Experience in using mobile related applications including education

\begin{tabular}{|l|c|c|}
\hline & Frequency & Percent (\%) \\
\hline $1-3$ Years & 6 & 20.0 \\
\hline 4 - 6 Years & 23 & 76.7 \\
\hline 7 - 9 Years & 1 & 3.3 \\
\hline Total & $\mathbf{3 0}$ & $\mathbf{1 0 0 . 0}$ \\
\hline
\end{tabular}

During the demonstration, almost all participants wanted to know how the prototype works (its functionalities), how to access the prototype, it, how to navigate its interface and the rate of uploading/downloading materials, and whether the prototype generally solved practical problems which were facing students and teachers at CBE then. The analysis was done using a descriptive analysis whereby the mean was taken to be the unit of measure. The score above 3 was taken to be high and agreeable. The mean score of 3.0 or below was taken to be low and disagreeable (see Table 8).

The findings showed that the access to the prototype was difficulty during the demonstration. Most of the participants struggled and constantly sought help with accessing the prototype. Similarly, the demonstrators struggled to connect and get access to prototype. It became evident that a construct that read "The CBEMET Prototype is not well suited for the purpose of teaching and learning" received very low score. This indicates that even though there were some difficulties in the access of the prototype, generally the prototype can be used for the purpose of mobile teaching and learning. However, the navigation of the interface of the prototype, uploading and downloading educational materials scored highly. Additionally, almost all 30 teachers recommended the addition of more options in the prototype like timetabling, live chart and students' access to the prototype.

\section{PART B - initial evaluation of the artifact}

This part narrates about a quick evaluation of the artifact following the demonstration. It is termed as a quick evaluation because the participants had to work with the artifact after the evaluation and compared to what they were expected to see on the working of the artifact during the workshops prior to demonstrations. The evaluation was done in terms of the functionality of the artifact, its ability to facilitate training through mobile devices, and facilitation in sharing of education resources. Table 8 shows the quick evaluation of the artifact in terms of functionalities of the artifact. 
Table 8. The first part is the evaluation on the functionalities of the artifact $(\mathrm{N}=30)$

\begin{tabular}{|l|c|c|}
\hline & Mean & Std. Dev. \\
\hline Access the CBEMET Prototype is difficult and complicated & 3.1333 & 1.04166 \\
\hline $\begin{array}{l}\text { The CBEMET Prototype has adequate facilities and capabilities to support mobile } \\
\text { teaching }\end{array}$ & 3.8333 & .83391 \\
\hline $\begin{array}{l}\text { The interface of the CBEMET Prototype makes it easier to navigate through } \\
\text { different services available in the prototype }\end{array}$ & 3.6667 & .88409 \\
\hline $\begin{array}{l}\text { The rate of uploading and downloading educational materials through the } \\
\text { CBEMET Prototype are satisfactory }\end{array}$ & 3.7333 & .98027 \\
\hline The CBEMET Prototype is not well suited for the purpose of teaching and learning & 2.4333 & 1.25075 \\
\hline $\begin{array}{l}\text { The CBEMET Prototype needs more options such as timetabling, live chart, and } \\
\text { students' access }\end{array}$ & 4.8333 & .37905 \\
\hline
\end{tabular}

One of the identified main practical pedagogical problems facing teachers at CBE was the lack of mobile training for teachers and students. The challenge at this point in time was how to deal with online training, how to prepare suitable materials for sharing online through a mobile education application, and how to implement an effective mobile teaching. According to the findings from the demonstration, some improvement should be done to the prototype to effectively meet these objectives. For example, the demonstrated proved that video lessons lacked creativity and were seemingly inappropriate. In addition, supporting illustrations were not that good and sound was not clear. The elements thus had high mean score to the negative statements (i.e. from Mean=3.8667) see Table 9. The participants thus suggested for the improvement of the online courses to the model of Cousera courses, which combines variety of courses and certificates online. Coursera has been successful in offering professional certificate programs online [26]. Further, the construct that read, "The CBEMET Prototype is well suited for mobile teaching" received very low score (Mean=2.4333), which suggests that if well re-designed to deal with the shortcomings CBEMET will surely help in mobile pedagogy mission at CBE.

Table 9. In bThe facilitation of education through mobile devices

\begin{tabular}{|l|c|c|}
\hline & Mean & Std. Dev. \\
\hline $\begin{array}{l}\text { The video lessons on the CBEMET Prototype are inappropriate and are hard to } \\
\text { understand }\end{array}$ & 3.8667 & .62881 \\
\hline $\begin{array}{l}\text { Supporting illustrations in the mobile training are inadequate and difficult to } \\
\text { understand }\end{array}$ & 4.0000 & .64327 \\
\hline $\begin{array}{l}\text { The quality of sound is poor such that one cannot follow what is being narrated } \\
\text { easily }\end{array}$ & 4.2000 & .80516 \\
\hline $\begin{array}{l}\text { The CBEMET Prototype needs more options to enable online training in the } \\
\text { model of Cousera courses } \text { which are very successful }\end{array}$ & 4.8333 & .37905 \\
\hline The CBEMET Prototype is not well suited for mobile teaching & 2.4333 & 1.25075 \\
\hline
\end{tabular}

Another crucial issue was the fact that CBE has four campuses at different geographical areas. As a result, a mismatch in teaching notes, syllabus, examinations and so forth was reported across the campuses. That is, the same subject for the same level (certificate, diploma, bachelor, and masters) would be taught using different materials and in different intensity. The problem implied the need for an application that would 
enable the smooth sharing of educational-related materials among the four campuses to ensure academic excellence and quality education. Consonantly, the demonstration showed that CBEMET facilitates downloading educational materials quite satisfactorily. However, uploading of materials appeared difficult (see Table 10). The demonstration revealed that CBEMET effectively facilitates sharing of materials through "Shared Contents" folder. The sharing of educational materials thus received positive responses from the participants who could at least get a glance of how the prototype could provide when all the feedback of the demonstration for the improvement has been worked out. Remember, in the DSR framework, the process is iterative such that after the demonstration, the re-designing and development can be done to accommodate the changes.

Table 10. Sharing of educational contents through the artifact.

\begin{tabular}{|l|c|c|}
\hline & Mean & Std. Dev. \\
\hline $\begin{array}{l}\text { It is not easy to upload education resources through the CBEMET Prototype } \\
\text { It is easy to download education resources through the CBEMET Prototype if } \\
\text { the Internet is good, otherwise it is difficult }\end{array}$ & 3.0667 & 1.11211 \\
\hline $\begin{array}{l}\text { There are abundant different education resources to access through the } \\
\text { CBEMET Prototype }\end{array}$ & 4.4000 & .49827 \\
\hline $\begin{array}{l}\text { Sharing of educational resources through the CBEMET Prototype is encourag- } \\
\text { ing }\end{array}$ & 4.1667 & .59209 \\
\hline $\begin{array}{l}\text { Whenever I browse shared learning content through the CBEMET Prototype, I } \\
\text { come across new and interesting education materials }\end{array}$ & 4.5333 & .62606 \\
\hline
\end{tabular}

\section{Discussion}

The CBEMET Prototype was demonstrated to teachers who had participated in its co-design and development. The goal of the demonstration stage was to check out if the artifact solved some of practical problems identified in the context in which it is applied. The demonstration was preceded with agreement by all parties on what to evaluate and what to evaluate. It included several activities such as accessing, uploading, and downloading documents. All activities were being recorded to determine aspects of CBEMET Prototype which are effective. The demonstration of the CBEMET Prototype revealed to teachers that some of their practical problems they were facing can be minimized through the prototype. The participants were very happy with "Shared Contents" folder which enabled uploading and sharing documents quite successfully (see Figure 9). Nonetheless, the demonstration revealed that some aspects of the prototype such as training videos and quality of sound needed improvement. 


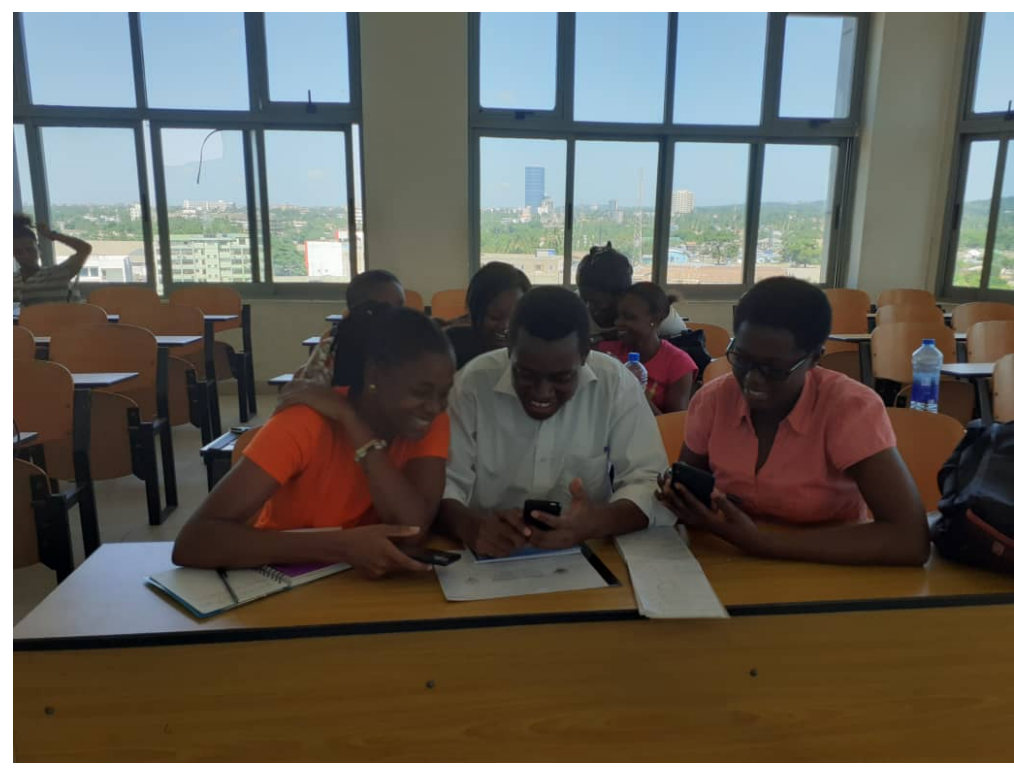

Fig. 8. Students witnessing the sharing of education contents during the demonstration

The results of the demonstration of CBEMET Prototype show that that the prototype matches Ford et al's., mobile education tool known as MobilEd tool [27] . MobilEd, this is a mobile education prototype which enables learners to capture information, take photos, record, store, compile slides for presentations and send them to the MMS'ing to the server for sharing. Further, it is in line with Solomon et al's., [10] MobileEdu which successfully helped students in a Nigerian university to learn computer science subjects and was tested and demonstrated in real-life settings as was done with the CBEMET Prototype.

Limitations of the study: The co-designing, development and demonstration of this prototype involved only 30 teachers. A reliable demonstration and initial evaluation would need a larger sample, which means that this demonstration serves only as pilot. Likewise, members of a students' organization body known as College of Business Education Students' Organization (COBESO) were invited as the potential users of the CBEMET Prototype but due to tight examination schedules they did not attend. The failure to attend of the COBESO members was a big blow as one of their tasks is to oversee the students' affairs and the exercises of demonstration of the prototype would have given them good ground in case of any pedagogical problems to students' in using the prototype. Further, demonstration and evaluation of the prototype was limited to one campus only of Dar es Salaam. In the future the demonstration and evaluation of the prototype will be done in all the four campuses to get a wider and more concrete overview of the prototype. The representative feedback will thus inform the improvement of the prototype into a fully-fledged mobile education application. 


\section{Conclusion}

The demonstration of the CBEMET Prototype to teachers at CBE achieved three main milestones. Firstly, it successfully employed DSR framework in the description of iterative stages of developing artifacts. Secondly it involved teachers in counterchecking of the effective of the prototype in solving the problem it was intended for. Thirdly, it provided a chance for improving the prototype in the coming iterations. The CBEMET Prototype is thus a proof that the use of mobile education applications in enhancing pedagogical activities in higher education institutions in Tanzanian is gaining momentum. The mobile learning (M-learning) facilitates teaching and learning everywhere and any time regardless of geographical location. This tremendous development in the education sector is attributed to the abundance of mobile operators, availability of internet (wired and wireless) and affordability of mobile devices to most teachers and students. As put forward by Shah, et al. [28], advanced technologies and mobile devices the implementation of M-learning can lead to innovative instructors and students with competitive standing with developed countries.

\section{$4 \quad$ References}

[1] H. Hare, "Survey of ICT and Education in Africa: Tanzania Country Report," World Bank, 2007.

[2] G. I. Mwandosya, C. Suero Montero, E. R. Mbise, E. T. Lwoga, R. Casmir and M. N. Mwasaga, "Improving higher education institutions' innovative teaching and learning in Tanzania through Information Communications Technology Tools," in ICONIC, Port Louis, 2018. https://doi.org/10.1109/iconic.2018.8601210

[3] M. P. J. Mahenge and C. Sanga, "ICT for e-Learning in Three Higher Education Institutions in Tanzania," Knowledge Management \& E-Learning, vol. 8, no. 1, pp. 200-212, 2016. https://doi.org/10.34105/j.kmel.2016.08.013

[4] J. C. Byungura, H. Hansson, K. Masengesho and T. Karunaratne, "ICT Capacity BUilding: A Critical Discourse Analysis of Rwandan Policies from Higher Education Perspective," European Journal of Open, Distance and e-Learning, vol. 19, no. 2, pp. 47-62, 2016. https://doi.org/10.1515/eurodl-2016-0007

[5] N. Tyilo, "E-Learning as Instructional Innovation in Higher Education Institutions (HEIs): Lessons Learnt from the Literature," Journal of Communication, vol. 8, no. 1, pp. 87-93, 2017. https://doi.org/10.1080/0976691x.2017.1305687

[6] A. Kukulska-Hulme, "Mobile Learning and the Future of Learning," vol. 2, pp. 13-18, 2012.

[7] A. R. Hevner, P. J. March and S. Ram, "Design Science in Information Systems Research," Management Information Systems Quarterly (MIS), vol. 28, pp. 75-105, 2004. https://doi.org/10.2307/25148625

[8] A. R. Hevner and S. Chatterjee, "Design Science Research in Information Systems: Theory and Practice," in Design Research in Information System, Boston, MA., Springer, 2010.

[9] P. Johannesson and E. Perjons, An Introduction to Design Science Research, Zurich, Switzerland: Springer International Publishing, 2014. 
[10] S. S. Oyelere, J. Suhonen, G. M. Wajiga and E. Sutinen, "Design, Development, and Evaluation of a Mobile Learning Application for Computer Science Education," Education and Information Technologies, 2017. https://doi.org/10.1007/s10639-017-9613-2

[11] K. A. Nihuka and J. Voogt, "Instructors and Students Competences, Perceptions and Access to E-Learning Technologies: Implications for E-Learning Implementation at the Open University of Tanzania," International Journal on E-Learning, vol. 10, no. 1, pp. 63-85, 2011.

[12] M. Tedre, F. Ngumbuke and J. Kemppanien, "Infrastructure, Human Capacity, and High Hopes: A Decade of Development of e-Learning in a Tanzanian HEI," RUSC. Universities and Knowledge Society Journal, vol. 7, no. 1, pp. 7-20, 2010. https://doi.org/10.7238 /rusc.v7i1.658

[13] W. Mtega, R. Bernard, A. C. Msungu and R. Sanare, "Using Mobile Phones for Teaching and Learning Purposes in Higher Learning Institutions: The Case of Sokoine University of Agriculture in Tanzania," in Proceedings and Report of the 5th UbuntuNet Alliance Annual Conference, Dar es Salaam, 2012. https://doi.org/10.4314/udslj.v10i1-2.43419

[14] J. S. Mtebe, A. Kondoro, M. M. Kissaka and E. Kibga, "Using SMS Mobile Technology to Assess the Materly of Subject Content Knowledge of Science and Mathematics Teachers of Secondary Schools in Tanzania," International Journal of Social, Behaviora, Educational, Economic, Business and Electrical Engineering, vol. 9, no. 11, pp. 3482-3490, 2015.

[15] J. S. Mtebe and A. W. Kondoro, "Using Mobile Moodle to Enhance Moodle LMS Accessibility and Usage at the University of Dar es Salaam," in IST-Africa Conference Proceedings, 2016. https://doi.org/10.1109/istafrica.2016.7530649

[16] J. S. Mtebe and R. Raisamo, "Investigating Perceived Barriers to the Use of Open Educational Resources in Higher Education in Tanzania," The International Review of Research in Open and Distance Learning, vol. 15, no. 2, pp. 43-66, 2014. https://doi.org/10.19173 /irrodl.v15i2.1803

[17] M. Grimus, M. Ebner and A. Holzinger, "Mobile Learning as a Chance to Enhance Education in Developing Countries - On the Example of Ghana," in Proceedings of the 11th International Conference on Mobile and Contextual Learning mLearning 2012, Helsinki, Finland., 2012.

[18] J. S. Mtebe and R. Raisamo, "Challenges and Instructors' Intention to Adopt and Use Open Resources in Higher Education in Tanzania," The International Review of Research in Open and Distance Learning, vol. 15, no. 1, pp. 249-271, 2014. https://doi.org/10.19173 /irrodl.v15i1.1687

[19] G. I. Mwandosya, C. S. Montero and E. R. Mbise, "Exploring the Acceptance of Mobile Technology Application for Enhancing Teaching and Learning at the College of Business Education in Tanzania," in Information Systems and Technologies to Support Learning, Fes, Morocco., EMENA-ISTL 2018, 2018. https://doi.org/10.1007/978-3-030-03577-8_20

[20] J. Krogstie, "Bridging Research and Innovation by Applying Living Labs for Design Science," in Nordic Contributions in IS Research, vol. 124, Berlin, Springer Berlin Heidelberg, 2012, pp. 161-176. https://doi.org/10.1007/978-3-642-32270-9 10

[21] K. Peffers, T. Tuunanen, M. A. Rothenberger and S. Chatterjee, "A Design Science Methodology for Information Systems Research," Journal of Management Information Systems, vol. 24, pp. 45-77, 2007. https://doi.org/10.2753/mis0742-1222240302

[22] J. S. Mtebe, "Learning Management System Success: Increasing Learning Management Usage in Higher Education in Sub-Saharan Africa," International Journal of Education and Development Using Information and Communication Technology, vol. 11, no. 2, pp. 5164, 2015. 
[23] G. I. Mwandosya and C. Suero Montero, "Towards a Mobile Education Tool for Higher Education Teachers: A User Requirements Definition," in Proceedings of the 2017 IEEE Science Technology \& Innovation for Africa Conference (AFRICON2017) Advancing Technology for Humanity, Capetown, South Africa., 2017. https://doi.org/10.1109/afrcon .2017 .8095598

[24] A. F. Kapinga, C. Suero Montero and E. R. Mbise, "Mobile marketing application for entrepreneurship development: Codesign with women entrepreneurs in Iringa, Tanzania," Electronic Journal of Information System Development, pp. 1-15, 2019. https://doi.org/10.1002/isd2.12073

[25] R. Braun, M. Benedict, H. Wendler and W. Esswein, "Proposal for Requirements Driven Design Science," in New Horizons in Design Science: Broadening the Research Agenda, Lecture Notes in Computer Science, Springer International Publishing, 2015, pp. 135-151. https://doi.org/10.1007/978-3-319-18714-3_9

[26] Cousera, "Coursera - Online Courses \& Credentials by Top Educators," Coursera, [Online]. Available: https//www.coursera.org. [Accessed 15 November 2019]. https://doi.org/10.4135/9781483318332.n95

[27] M. Ford and T. Leinonen, "MobilED- A Mobile Tools and Services Platform for Formal and Informal Learning," in mLearn 2006, the 5th World Conference on Mobile Learning, Banff, Canada, 2006.

[28] A. Shah, Suhailiezana., C. K. Che Ghan and M. Khairudin, "Effectiveness of m-Learning for Design and technology Subject," International Journal of Interactive Mobile Technologies, vol. 13, no. 10, pp. 120-133, 2019. https://doi.org/10.3991/ijim.v13i10.11324

\section{Authors}

Godfrey Isaac Mwandosya is in the College of Business Education at Dar es Salaam Campus in Dar es Salaam city of Tanzania. g.mwandosya@cbe.ac.tz

Calkin Suero Montero is with University of Eastern Finland in Finland. calkins@uef.fi

Esther Rosinner Mbise is with Dar es Salaam Campus of Dar es Salaam in Tanzania.ermbise@gmail.com

Solomon Sunday Oyelere is with University of Eastern Finland in Finland. solomon.oyelere@uef.fi

Article submitted 2020-01-15. Resubmitted 2020-05-03. Final acceptance 2020-05-07. Final version published as submitted by the authors. 